\title{
Use of Recycled Tyre Rubber in Non-structural Concrete
}

\author{
Muhammad Bilal Waris ${ }^{1,{ }^{*}}$, Hussain Najwani ${ }^{1}$, Khalifa Al-Jabri ${ }^{1}$, and Abdullah Al-Saidy ${ }^{1}$ \\ ${ }^{1}$ Department of Civil and Architectural Engineering, Sultan Qaboos University, P.O. Box: 33, \\ P.C. 123, Muscat, Sultanate of Oman.
}

\begin{abstract}
To manage tyre waste and conserve natural aggregate resource, this research investigates the use of waste tyre rubber as partial replacement of fine aggregates in non-structural concrete. The research used Taguchi method to study the influence of mix proportion, water-tocement ratio and tyre rubber replacement percentage on concrete. Nine mixes were prepared with mix proportion of 1:2:4, 1:5:4 and 1:2.5:3; water-to-cement ratio of $0.25,0.35$ and 0.40 and rubber to fine aggregate replacement of $20 \%, 30 \%$ and $40 \%$. Compressive strength and water absorption tests were carried out on $100 \mathrm{~mm}$ cubes. Compressive strength was directly proportional to the amount of coarse aggregate in the mix. Water-to-cement ratio increased the strength within the range used in the study. Strength was found to be more sensitive to the overall rubber content than the replacement ratio. Seven out of the nine mixes satisfied the minimum strength requirement for concrete blocks set by ASTM. Water absorption and density for all mixes satisfied the limits applicable for concrete blocks. The study indicates that mix proportions with fine to coarse aggregate ratio of less than 1.0 and $\mathrm{w} / \mathrm{c}$ ratio around 0.40 can be used with tyre rubber replacements of up to $30 \%$ to satisfy requirements for non-structural concrete.
\end{abstract}

\section{INTRODUCTION}

Disposal of used tyres is a significant environmental concern around the globe. Landfills of countries worldwide contain millions of waste tyres [1]. In Oman, three million used tyres are dumped in Dhofar region only, which can produce 20,000 tons of raw materials upon processing [2]. According to the World Health Organization (WHO) more than 800,000 new vehicles were registered in Oman in the year 2010 [3]. On the other hand, the extensive excavation of aggregates for concrete manufacturing is another rising environmental and industrial concern. The depletion of these resources has resulted in a steady rise in aggregate prices that may go as much as $50 \%$ higher than current values in a few years [4].

Many efforts have been made in order investigate use of recycled tyre rubber in construction industry. The most common application is rubberized asphalt concrete (RAC) that has proven effective for decades. In recent years, application of recycled tyre rubber in

\footnotetext{
* Corresponding author: waris@squ.edu.om
} 
concrete manufacturing has been investigated by considering replacement of aggregates with tyre crumbs of suitable size [5-9]. The conclusion was that use of rubber in concrete decreases its strength significantly; rubber is a weak material and leads to earlier onset of micro-cracking in the concrete matrix. The degradation in strength, limits the use of tyres for replacement on aggregates in structural concrete. This study, therefore, investigates the effect of tyre replacement on non-structural concrete by applying the Taguchi's method of experiments [10]. The study shall consider the effects of mix proportion, water-to-cement ratio $(\mathrm{w} / \mathrm{c})$ and percentage replacement of fine aggregates with tyre rubber on density, water absorption and compressive strength.

\section{Methodology}

The study applied the Taguchi's method for design of experiments [10] that is used for optimization of constituents of a product. The method recommends selective sample preparation and testing based on the number of parameters and their values considered for optimization. Recommendations of American Society for Testing and Materials (ASTM) [11] and Oman Concrete Products (OCP) [12] are considered as reference for optimization of the properties of concrete mixes prepared in this study. According to ASTM C129 [11], the minimum acceptable compressive strength of the average of three units is $4.14 \mathrm{MPa}$, while OCP [12] specifies a minimum average of three units as $7.5 \mathrm{MPa}$ with a minimum average density of $1.40 \mathrm{~g} / \mathrm{cm}^{3}$ and water absorption not exceeding $15 \%$. The study utilized $100 \mathrm{~mm}$ cubes to examine the compressive strength, density and water absorption of the mixes used in the study [13].

\subsection{Experiment Scheme}

Oman Concrete Products (OCP) [12] uses a mix proportion of 1:5:4 (cement: fine aggregate: coarse aggregate) with a $\mathrm{w} / \mathrm{c}$ ratio of 0.40 . The coarse aggregate used are $10 \mathrm{~mm}$ down only. The study used three values for each parameter (mix proportion, w/c ratio and rubber replacement) and employed the Taguchi's method of experiments [10] to develop the test scheme. The w/c ratio of $0.25,0.35$ and 0.40 , mix proportions of 1:2.5:3, 1:2:4 and 1:5:4 along with tyre rubber replacement (TR) of $20 \%, 30 \%$ and $40 \%$ were used. The test scheme was based on the L9 table of Taguchi's method [10] as summarized in Table 1. A control mix is not considered since the goal is to achieve the desired strength and physical characteristics specified by OCP [12] and ASTM [11].

Table 1 Experiment Scheme

\begin{tabular}{|l|l|l|l|}
\hline Mix ID & Mix Proportion* & w/c ratio & Tyre replacement \\
\hline M-1 & $1: 2: 4$ & 0.40 & $20 \%$ \\
\hline M-2 & $1: 5: 4$ & 0.40 & $30 \%$ \\
\hline M-3 & $1: 2.5: 3$ & 0.40 & $40 \%$ \\
\hline M-4 & $1: 2: 4$ & 0.35 & $30 \%$ \\
\hline M-5 & $1: 5: 4$ & 0.35 & $40 \%$ \\
\hline M-6 & $1: 2.5: 3$ & 0.35 & $20 \%$ \\
\hline M-7 & $1: 2: 4$ & 0.25 & $40 \%$ \\
\hline M-8 & $1: 5: 4$ & 0.25 & $20 \%$ \\
\hline M-9 & $1: 2.5: 3$ & 0.25 & $30 \%$ \\
\hline
\end{tabular}




\begin{tabular}{|l|l|l|l|}
\hline Mix ID & Mix Proportion* & w/c ratio & Tyre replacement \\
\hline *Cement: Fine Aggregate: Coarse Aggregate \\
\hline
\end{tabular}

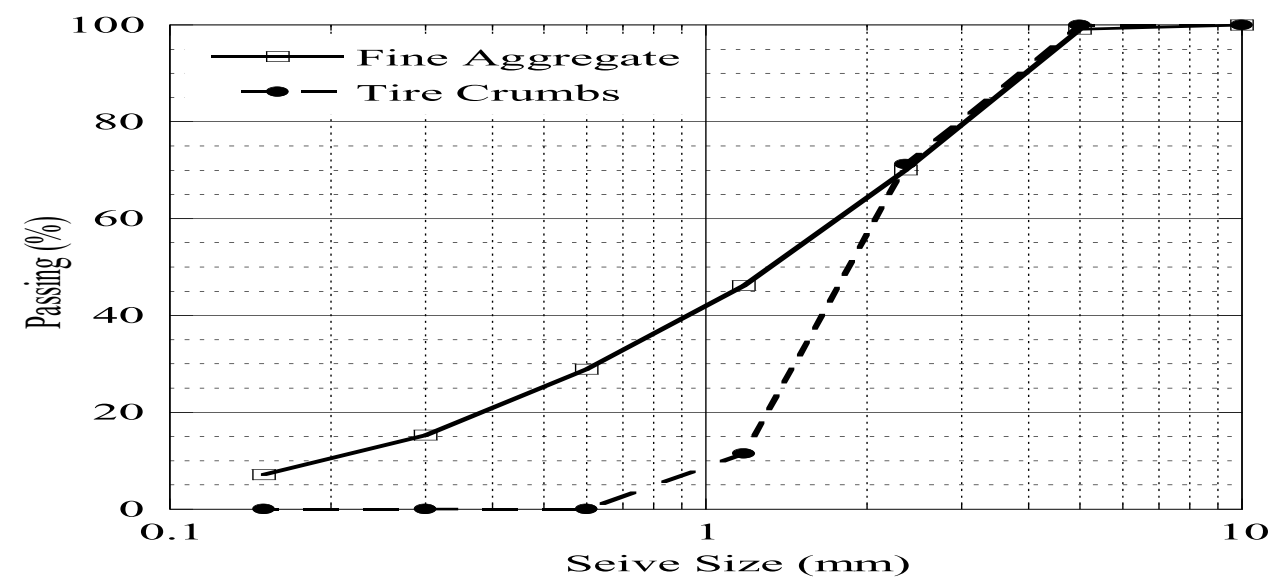

Fig. 1 Particle Size Gradation for Fine Aggregates and Crumbed Tyre Rubber

\subsection{Material}

The concrete was prepared using locally available ordinary Portland cement (ASTM: TypeI). The coarse aggregate (10 $\mathrm{mm}$ down) and fine aggregates (5 $\mathrm{mm}$ down) used were conforming to Omani Standards [14]. The recycled tyre crumbs used for replacement of fine aggregates ranged from 0.80 to $4 \mathrm{~mm}$. The gradation curve of the rubber crumbs and fine aggregates used in this study is shown in Fig. 1. It is clear that most of the crumbs $(\approx$ $60 \%$ ) are within the size range $1.18-2.36 \mathrm{~mm}$. Specific gravities of coarse aggregate, fine aggregate and tyre rubber were estimated to be $2.69,2.85$ and 1.05 respectively.

\subsection{Batch Quantities}

The percentage replacement of fine aggregates with tyre crumbs used in this study is based on volume. The mass of tyre rubber required for a particular mix was calculated using specific gravity of fine aggregate and tyre crumbs. Eq (1) and (2) were used to calculate the amounts of aggregate and recycled tyre for a given replacement fraction " $\alpha$ ".

$$
\begin{aligned}
& m_{\alpha, \text { tire }}=m_{\text {agg }} \times \alpha \times S G_{\text {tire }} / S G_{\text {agg }} \\
& m_{\alpha, \text { agg }}=(1-\alpha) \times m_{\text {agg }}
\end{aligned}
$$

Where; $\alpha=$ fractional replacement of aggregate considered $(0.20,0.30$ or 0.40$)$; ' $\mathrm{m}_{\alpha, \text { Tyre }}$ ' is mass of tyre rubber to be used with ' $\alpha$ ' replacement; ' $\mathrm{m}_{\mathrm{agg}}$ ' is the total mass of aggregate in the control mix; ' $\mathrm{m}_{\alpha, \text { agg' }}$ ' is mass of aggregate in the mix having ' $\alpha$ ' replacement; ' $\mathrm{SG}_{\mathrm{Tyre}}$ ' and ' $\mathrm{SG}_{\mathrm{agg}}$ ' are specific gravity of tyre rubber and aggregate respectively. The quantity of water includes allowance for water absorption of coarse, fine aggregates and tyre crumps which were estimated to be $3 \% 2 \%$ and $7 \%$, respectively. The quantities for the tyre crumbs and fine aggregates are calculated using eq- 1 and eq- 2 , respectively. 


\subsection{Samples and Tests}

A total of four $100 \mathrm{~mm}$ cubes were sampled for each mix. The samples were removed from moulds after 24 hours of casting and cured in water tanks for 28 days. The density is reported as the average of all the four samples, the compressive strength is reported as the average of three while the water absorption was measured for one sample only.

\section{Results and Discussion}

Figure 2, Figure 3 and Figure 4 show the density, compressive strength and water absorption for the mixes respectively. The figures summarize the result in terms of $\mathrm{w} / \mathrm{c}$ ratio, fine-to-coarse aggregate ratio and tyre replacement ratio. In Figure 2, it can be observed that the density increases with increase in w/c ratio owing to higher water content that result in better compaction due to improvement in workability. The density tends to decrease with increase in fine-to-coarse ratio while rubber replacement also shows the same trend. The variation trends indicate that low w/c ratio or high fine-to-coarse ratio is more likely to lower concrete density compared to higher tyre replacement.
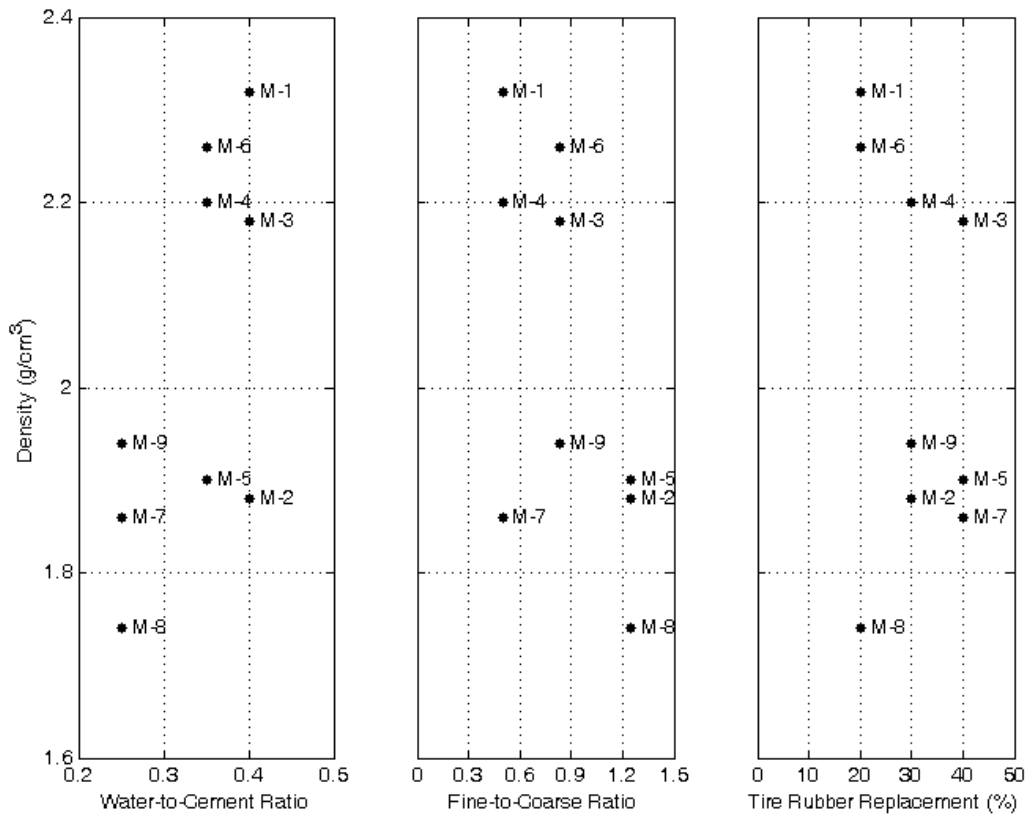

Fig. 2. Density as Function of W/C Ratio, Fine-Coarse Ratio and Tyre Replacement 

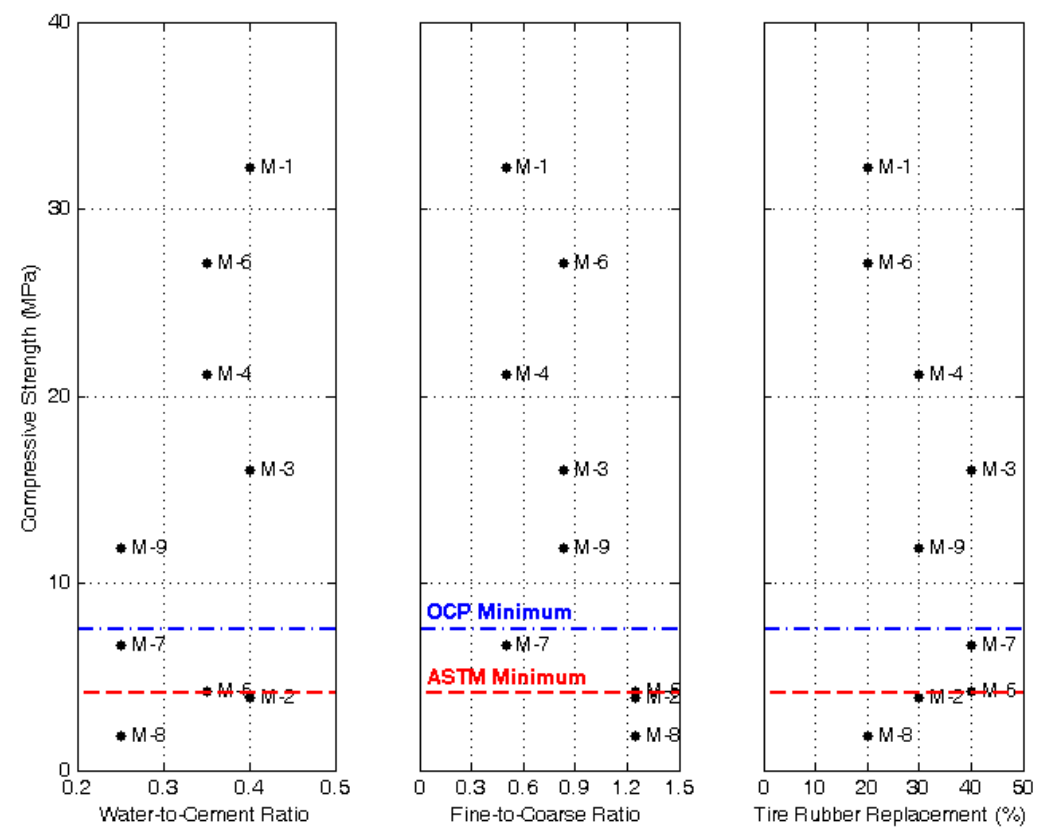

Fig. 3 Compressive Strength as Function of W/C Ratio, Fine-Coarse Ratio and Tyre Replacement
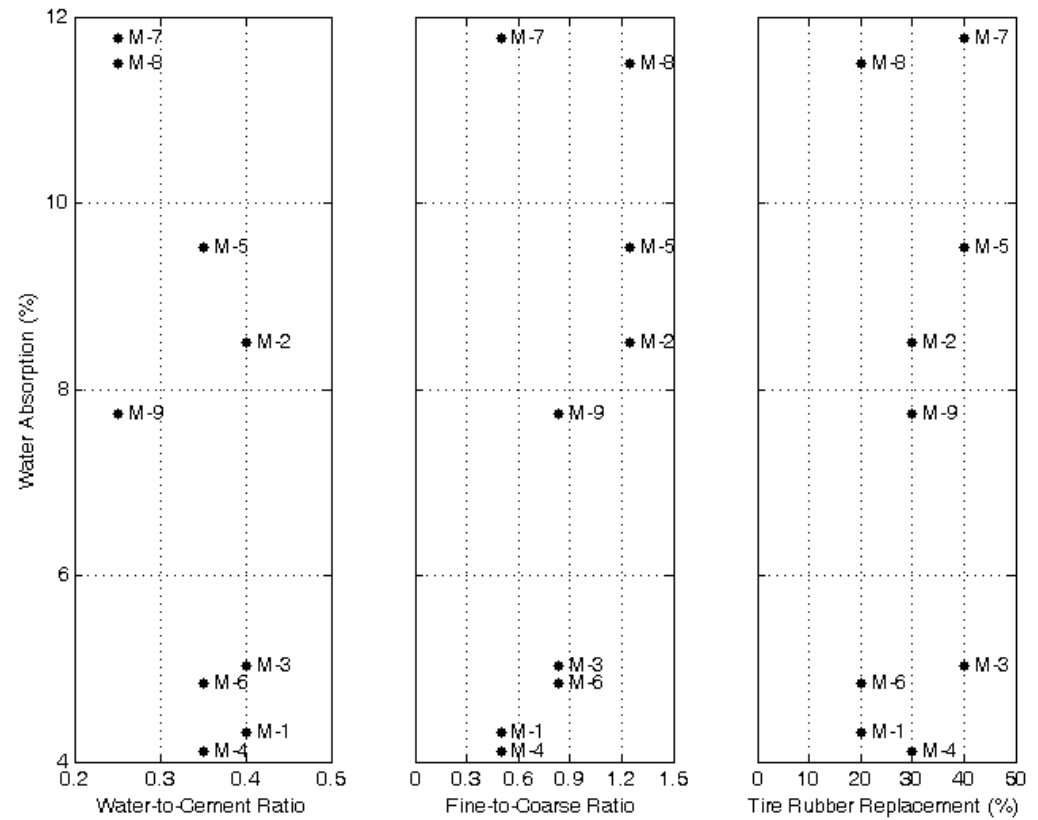

Fig. 4 Water Absorption as Function of W/C Ratio, Fine-Coarse Ratio and Tyre Replacement

Figure 3 shows the variation in compressive strength under the same parameters along with limits from ASTM and OCP discussed earlier. Compressive strength shows in increasing trend with increase of $\mathrm{w} / \mathrm{c}$ ratio while the variation in strength increases that can be attributed to variation in other parameters. Two mixes (M-7 and M-8) with the lowest $\mathrm{w} / \mathrm{c}$ ratio could not fulfil OCP requirements. The strength decreases with increase in fine aggregate content with reduced variation among mixes with the same fine-to-coarse ratio. It 
can be observed that the strength is most adversely affected by fine-to-coarse ratio since all three mixes (M-2, M-5 and M-8) with the highest fine-to-coarse ratio (1.25) fail the OCP criterion. As anticipated the strength decreases with increase in tyre rubber content, with two out of the three mixes with $40 \%$ replacement (M-5 and M-7) failing to satisfy OCP limit. The highest rubber content is in mix M-5 i.e, $8.4 \%$ but it still provides higher strength compared to mix M-8 with 3.9\% rubber content. Mixes M-2 and M-3 have the same rubber content (approx. $6.3 \%$ ) and the same w/c ratio $=0.40$ but $\mathrm{M}-3$ provides nearly four times strength compared to M-2 due to difference in coarse aggregate content. Similarly, mix M7 and M-9 have similar rubber content (approx. $4.6 \%$ ) and same $\mathrm{w} / \mathrm{c}$ ratio $=0.25$ but show a twofold difference in strength. This indicates that the coarse aggregate content in the mix has very dominant influence on concrete strength.

In Figure 4, the water absorption does not indicate clear trends due to the large variation in values for the parameter considered. All the values, however, are observed to be less than the limit of $15 \%$ set by OCP. The mixes [M-7 and M-8] with the highest water absorptions are the ones with the lowest $\mathrm{w} / \mathrm{c}$ ratio indicate that $\mathrm{w} / \mathrm{c}$ ratio is more critical compared to mix proportion and tyre replacement as both these mix have either the minimum or maximum values of fine-to-coarse ratio and rubber replacement percentage.

\section{Conclusions}

The study used Taguchi's method of experiments to investigate the influence of w/c ratio, mix proportion (fine aggregate to coarse aggregate ratio) and replacement of fine aggregates with tyre rubber on the density, water absorption and the compressive strength of resulting concrete mixes. Three levels of each parameter were considered to prepare nine mixes. Specifications by OCP and ASTM were considered as bench reference for acceptance of a mix. All the mixes satisfied the density and water absorption requirement while only six mixes satisfied ASTM requirement for compressive strength. Only one mix with $40 \%$ rubber replacement satisfied this limit while two from both $20 \%$ and $30 \%$ did achieve the required compressive strength. Concrete with tyre rubber replacement can therefore be considered as a potential candidate for use in concrete block making.

\section{References}

1. S. Banyopadhyay, S.L. Agrawal, R. Ameta, S. Dasgupta, R. Mukhopadhyay, A.S Deuri, S.C. Ameta, R. Ameta, An Overview of Rubber Recycling, Prog. in Rub., Plast. and Recyc.Tech. 24: 73-112 (2008)

2. COWI, (www.cowi.com/oman)

3. Global Health Observatory Data Repository, World Health Organization (WHO).

4. R. Wile, There is not Enough Sand to Satisfy America's Insatiable Fracking Demand, Business Insider Indonesia, Sep 1, (2014)

5. K.C. Panda, P.S. Parhi, T. Jena. Scrap-Tire-Rubber Replacement for Aggregate in Cement Concrete: Experimental Study, Int. J. Ear. Sci. Engg., 05, 1692-1701 (2012)

6. V. Sandeep, N. Kumar, C. Sudharani. Using Tires Wastes as Aggregates In Concrete To Form Rubcrete - Mix For Engineering Applications', IJRET: International Journal Res. Engineering \& Technology. 3, 500-509 (2014)

7. M.B. Waris, N.N. Ali, and K.S. Al-Jabri. Use of Recycled Tire in Concrete for Partial Aggregate Replacement. International Journal of Structural and Civil Engineering Research, 5, 4, 273-276 (2016) 
8. Z. Al-Rawahi and M.B.Waris. Use of Recycled Tires in Non-structural Concrete. MATEC Web of Conferences, 120, 03002 (2017)

9. T. Gupta,,S. Chaudhary, R. Sharma. Assessment of Mechanical and Durability Properties of Concrete Containing Waste Rubber Tire as Fine Aggregate. Construction and Building Materials, 73, 562-574 (2014)

10. G. Taguchi, S. Konishi. Taguchi Methods, Orthogonal Arrays and Linear Graphs, Tools for Quality American supplier institute, American Supplier Institute: 8-35 (1987)

11. C129-14, Standard Specification for Non-loadbearing Concrete Masonry Units, ASTM International (2014)

12. Oman Cement Product (OCP), (www.ocpblock.com)

13. C140-12, Standard Test Methods for Sampling and Testing Concrete Masonry Units and Related Units, ASTM International. (2012)

14. Omani Standard OS2, Natural aggregate; Specification, Ministry of Commerce \& Industry, Directorate General for Specifications \& Measurements, Oman. (1982) 